\title{
ESTÁGIO NA FORMAÇÃO INICIAL DO CURSO DE PEDAGOGIA: ESCUTAS E LEITURAS
}

\author{
STUDENT TEACHING IN THE INITIAL TRAINING OF THE PEDAGOGY MAJOR: \\ HEARINGS AND READINGS
}

\section{PASANTÍA EN LA FORMACIÓN INICIAL DEL CURSO DE PEDAGOGÍA: ESCUCHAS Y LECTURAS}

\author{
Rejane Maria de Almeida Amorim* \\ Leny Cristina Soares Souza Azevedo*
}

\begin{abstract}
Resumo: O presente artigo propõe uma discussão sobre a formação inicial do professor e tem por objetivo apresentar o relato de experiências com estágios indicando limites e potencialidades vivenciadas nesse período. Este estudo é fruto de pesquisa - ação realizada com alunos do curso de Pedagogia de uma instituição de Ensino Superior durante o semestre em que cursaram as disciplinas de Prática de Ensino dos Anos Iniciais e Prática de Ensino em Política e Administração Educacional entre 2010 e 2012. A articulação das duas práticas é resultado de amplas discussões e trocas estabelecidas entre as professoras pesquisadoras, que percebem a fragilidade na formação do pedagogo, considerando que realizam seus estágios dentro de uma realidade contraditória: por um lado pretende a imersão no campo para que seja possível aprender com ele, e por outro formar para promover uma ruptura com práticas nem sempre alinhadas à qualidade pretendida. Desse modo, os estágios estão direcionados para construção dos saberes docentes, na tentativa de aprofundamento do debate e conhecimento do campo, para além de um semestre letivo, justamente a fim de compor em conjunto com as disciplinas teóricas o início da profissionalização do pedagogo. As análises partem de documento escrito pelos próprios acadêmicos, protagonistas de sua formação, em forma de relatório e portfólio de estágio que permitem refletir sobre estas experiências. Essas escutas e leituras contribuem sobremaneira para produção de um conhecimento potencialmente importante para todos aqueles que, ao conhecerem melhor a prática de formação inicial do pedagogo, possam compreender e aprofundar estudos sobre sua profissionalização.
\end{abstract}

Palavras - Chave: Prática de Ensino. Formação de professors. Estágio.

Abstract: This paper proposes a discussion about the Initial Teachers Education and aims to present an account of student teaching experiences which indicates limits and capabilities lived in this period. This study is the result of a research - action done with students of the Pedagogy major of a higher education institution during the semester in which they attended the following courses: Teaching Practice of Early Childhood and Teaching Practice in Educational Policy and Leadership, between 2010 and 2012. The articulation of both practices is the result of extensive discussions and established exchanges between professors researchers who perceive the weakness in the pedagogue's education; teacher's training, considering that they experience their teaching within a contradictory reality, on

\footnotetext{
*Professora Adjunta da Faculdade de Educação da Universidade Federal do Rio de Janeiro (UFRJ). Doutora no programa de Estudos Pós-Graduados em Educação: Psicologia da Educação na Pontifícia Universidade Católica de São Paulo. Email: rejane_almeida@hotmail.com

${ }^{* *}$ Professora Adjunto III da Universidade Federal do Rio de Janeiro. Doutora em Educação pela Universidade Estadual de Campinas. Email: leny.az@hotmail.com
} 
one hand it pretends to be an immersion field so that they can learn from it and, on the other hand, to promote a break with practices that do not always align the desired quality. Thus, those teaching experiences are targeted for the construction of teaching knowledge in an attempt to further debate and knowledge of the field beyond one semester, but exactly to combine theory with the beginning of the pedagogue professionalization. The analyses are from documents written by the students themselves, the protagonists of their education, as student teaching reports and portfolio that allow reflecting on these experiences. Those hearings and readings contribute greatly to produce a potentially important knowledge to all those who know best the practice of initial pedagogue training, who understand and deepen their studies about their professionalization.

Keywords: Teaching Practice. Teacher Education. Student Teaching.

Resumen: El presente artículo propone una discusión sobre la formación inicial del profesor y tiene por objetivo presentar el relato de experiencias con pasantía indicando límites y potencialidades vivenciadas en ese periodo. Este estudio es fruto de pesquisa - acción realizada con alumnos del curso de Pedagogía de una institución de Enseñanza Superior durante el semestre en que cursaron las asignaturas de Práctica de Enseñanza de los Años Iniciales y Práctica de Enseñanza en Política y Administración Educacional entre 2010 y 2012. La articulación de las dos prácticas es resultado de amplias discusiones y cambios establecidos entre las profesoras pesquisadoras, que perciben la fragilidad en la formación del pedagogo, considerando que realizan sus pasantías dentro de una realidad contradictoria: por un lado pretende la inmersión en campo para que sea posible aprender con él, y por otro formar para promover una ruptura con prácticas ni siempre aliñadas a la cualidad pretendida. De ese modo, los pasantes están direccionados para construcción de los saberes docentes, en la tentativa de profundizamiento del debate y conocimiento del campo, para allá de un semestre lectivo, justamente a fin de componer en conjunto con las disciplinas teóricas el inicio de la profesionalización del pedagogo. Los análisis parten de documento escrito por los propios académicos, protagonistas de su formación, en configuración de informe y pasta con documentos de pasantía que permiten reflejar sobre estas experiencias. Esas escuchas y lecturas contribuyen sobre todo para producción de un conocimiento potencialmente importante para todos aquellos que, al conocieren mejor la práctica de formación inicial del pedagogo, puedan comprender y profundizar estudios sobre su profesionalización.

Palabras-clave: Práctica de Enseñanza. Formación de profesores. Pasantía.

\section{O ponto de cruzamento da formação: experiências, leituras e escutas da disciplina Prática de Ensino}

A experiência do aluno em sua formação de professor acontece não apenas na sala de aula de estágio ou na sua aula com o professor da graduação. A riqueza dessa trajetória está na articulação dos saberes gerados em diferentes momentos: do aluno com ele mesmo, do aluno com outro aluno, da sua relação com o objeto de conhecimento e de todas essas possibilidades com o mundo.
Novos saberes emergem do movimento fluido entre parceiros de caminhada que em diferentes tempos modificam o foco de observação e rompem a barreira do imediato e elevam suas experiências para reflexão. Um aspecto teórico sem sentido pouco irá auxiliar o futuro professor, mas, congregado com outras vozes e leituras, constitui-se na base sobre a qual estará alicerçado.

Para que esses saberes se constituam, é necessário haver a dupla interação, tanto da parte do professor como do aluno, para que se possa realmente encontrar a dimensão que 
Charlot (2005) enfatiza e que assumimos em nosso processo de formador, do saber ser o próprio sujeito em relação ao mundo que o cerca e desse sujeito com ele mesmo. Desse modo para o autor: "O indivíduo não se define somente por sua posição social ou pela de seus pais; ele tem uma história; passa por experiências; interpreta essa história e essa experiência; dá sentido ao mundo, aos outros e a si mesmo. O sujeito é indissociavelmente social e singular.” (2005, p.40)

As trocas entre professoras do curso possibilitou que esse trabalho fosse realizado. Parar e rever o caminho trilhado, o fazer diário que configurou uma forma de existir do estágio em um determinado espaço e tempo na Faculdade de Educação, atitudes que se revelam como maiores que uma simples tarefa do ofício como pesquisadoras, mas que acabam condicionando um querer maior que possibilita a reflexão, teorização e percepção da importância dos estágios como momentos reflexão e construção do saber docente nos cursos de formação inicial de professores.

No que se refere à Prática de Ensino como disciplina, em atendimento às Diretrizes do Conselho Nacional de Educação, o currículo do curso dispersa em cinco itens a formação prática dos futuros professores - Educação de Jovens e Adultos, Educação Infantil, Magistério de Disciplinas Pedagógicas, Política e Administração Educacional, Séries Iniciais do Ensino Fundamental - cada uma com 180 horas de carga horária, cursadas uma por vez a partir do quinto período, sendo 120 horas de prática e 60 horas em sala de aula.

\section{O destaque para a Prática de}

Ensino nas Séries Iniciais do Ensino Fundamental

Respeitando premissas determinadas por lei e pela escolha curricular do curso, o fio norteador da Prática de Ensino nas Séries Iniciais é pensado a partir do quanto uma atividade de pesquisa é significativa para se fundir a essa prática. Utilizar a pesquisa para ampliar os horizontes dos alunos para além do imediato fazendo-os repensar a prática com um viés teórico se constituiu no maior desafio dessa disciplina.

O currículo do Curso de Pedagogia em questão está organizado atualmente prevendo 180 horas, no $8^{\circ}$ período, destinadas à formação prática de estágio para o trabalho com as Séries Iniciais, divididas entre 60 horas em sala de aula com o professor da disciplina que faz a mediação da teoria com a prática e 120 horas no campo de estágio. Ainda é possível utilizar 30 horas das 120 horas para realização de atividades científico-culturais, restando assim 90 horas para a prática na escola. Para melhor compreender essa divisão basta dizer que, se o aluno permanecer por 18 dias acompanhando uma classe em meio período, seu estágio está concluído.

Vale ressaltar que quando o estudante chega para esta prática já fez a Prática de Ensino em Política e Administração Educacional e, portanto, considerar que já esteve em uma escola e verificou os encaminhamentos que se referem a projetos, programas, currículo e organização da gestão constitui um caminho importante para esse novo movimento de se deparar com os desdobramentos de muitas decisões políticas e de escolhas institucionais que vão refletir na prática docente. Ressalte-se que a prática docente não se dá em portas fechadas, mas é o reflexo do social, do político, do currículo assumido e do movimento de todos esses fatores em conjunto com os saberes docentes.

Alguns alunos realizam a Prática das Séries Inicias e a Prática em Política e Administração Educacional na mesma escola, o que facilita a sua imersão na realidade 
escolar, possibilitando-lhe, assim, a reflexão sobre a articulação da gestão escolar com a vivência docente e discente na sala de aula. Seria o ideal que isso ocorresse sempre, como um aluno indica:

Realizei a minha prática em Política e Administração Educacional no XXXX e por esse motivo pude conhecer um pouco o funcionamento da escola e como eles se organizam. Durante o estágio de Política e Administração Educacional tivemos a oportunidade de entrar em sala poucas vezes, porém consegui perceber o quanto as crianças são conscientes, antenadas e curiosas. Isso me deixou encantada. Tal encantamento se transformou em vontade de retornar e vivenciar o trabalho realizado dentro da sala de aula, conhecer o processo de formação dessas crianças (...).

(Aluno 1 - Portfólio de estágio 2012/01)) ${ }^{1}$

\section{O destaque para a Prática de Ensino em Política e Administração Educacional}

A vivência e experiência como docente na disciplina Prática de Ensino em Política e Administração Educacional no curso de Pedagogia em instituição federal de nível superior tem sido marcadas pelas leituras das últimas décadas do século XX e que se estende no século XXI, sobre a convocação dos gestores para assumirem com a comunidade escolar a organização do ensino e o delineamento de propostas com a tendência coletiva. Registram-se, nesse propósito, tensões de longa duração entre a naturalização do "bem comum”, a partir de projetos fragmentados, centralizados e o caráter educativo de projetos participativos.

\footnotetext{
${ }^{1}$ Todos os estudantes serão identificados por número, preservando assim sua identidade, muito embora tenhamos autorização de reproduzir suas observações.
}

A participação, segundo Fonseca (2004), constitui, há algum tempo, um dos temas de destaque dos que se dedicam à gestão. Há uma estreita relação entre democracia e participação, porém, o autor chama a atenção para o fato de que "o termo tem sentido plural e, desse modo, a participação pode produzir formas multivariadas em sua aplicação prática, dependendo das finalidades e dos diversos contextos em que se materializa” (p.120).

Seja como for, construímos nas aulas do curso de Pedagogia, na Prática de Ensino em 2010, 2011 e 2012, discussões das observações feitas no estágio acerca das estratégias de organização e qualidade do ensino em escolas públicas que oferecem o curso médio normal. Essa prática de ensino na universidade tem como objetivo geral analisar as políticas e processos de gestão escolar, procurando demarcar as tendências e significados de seu desenvolvimento, indicando seus principais problemas.

Assim, os alunos em formação no $6^{\circ}$ período do curso de pedagogia se dirigem às escolas para observarem principalmente o trabalho da equipe gestora e perceberem como esse trabalho interfere na qualidade do processo de ensino e aprendizagem. A escolha dessas instituições que oferecem o ensino médio normal, pelos alunos estagiários de Pedagogia, justifica-se pelos seguintes motivos: 1) pela localização, facilitando o acesso; 2) a disponibilização da documentação necessária para a análise; 3) flexibilização do contato com os gestores, professores e jovens alunos do Ensino Médio normal.

Neste contexto, os alunos estagiários em Pedagogia refletem as contribuições e dificuldades na execução das ações dos gestores na elaboração e condução das suas práticas, examinando o projeto político-pedagógico e os Conselhos de Classe. Esse estágio de 180 horas compreende observações, análise da 
documentação escolar, discussão em pequenos grupos, mediado pela professora da disciplina, sobre o levantamento feito na escola, e elaboração de um relatório final reflexivo. Em sala de aula são feitos debates sobre os textos teóricos que referendam essas reflexões. Nos anos de 2010, 2011 e 2012 os alunos realizaram estágio nesses colégios de Ensino Médio e a partir da análise da produção dos relatórios é que este artigo foi construído.

\section{Prática de Ensino nas Séries Iniciais do Ensino Fundamental: reflexões de um aluno construindo seus saberes docentes}

A pluridimensionalidade do 'saber profissional' dos professores é referendada por Gauthier (1998. p. 11), para quem "o saber docente é um saber composto de vários saberes oriundos de fontes diferentes e produzidos em contextos institucionais e profissionais variados".

Em suas atividades pedagógicas diárias, os professores planejam, executam o plano didático, escolhem as metodologias que julgam condizentes, elaboram as tarefas para os alunos, administram a sala de aula mantendo a ordem e a disciplina e constroem os instrumentos de avaliação. Em outras palavras, os professores tratam da gestão da matéria e da gestão da sala de aula e, por isso, necessitam utilizar diferentes 'saberes' necessários à consecução dos objetivos previamente definidos.

Pensando nisso, o desenvolvimento das aulas de Prática de Ensino das Séries Iniciais foi se ajustando para que fosse possível permitir que o aluno compreendesse essa atividade como complexa, desafiadora e com múltiplos saberes específicos para além da matéria dada. Além do diálogo constante com outras práticas e disciplinas teóricas, realizamos uma proposta de formação cultural através de investidas no capital cultural dos próprios estudantes, incentivando e computando suas atividades científicas e culturais dentro de uma possibilidade de 30 horas complementares. Assim, os alunos cumpririam 90 horas na escola e mais 30 horas em atividades variadas que seriam encaminhadas pelos próprios estudantes e pela professora.

Um aluno comenta sobre esse caminho escolhido que dá margem para que haja a confluência de vários saberes, deixando claro o quanto o sentido que dá a sua formação é permeado por essa noção de importância da qualificação advinda de várias fontes:

Considero a formação cultural e a acadêmico científica como dois pilares da constituição profissional do pedagogo, além do conhecimento disciplinar e dos conhecimentos didáticos e pedagógicos. Parte da minha boa formação se deve ao meu investimento na melhor apropriação desses fatores. Um pedagogo adequadamente formado, adequadamente formará seus alunos. Essa é uma tarefa dos cursos de formação de professores: fazer com que a formação inicial se concretize em efetivo aprendizado discente. Buscarei, quando docente e pesquisador, contribuir neste debate, e essa organização discursiva proposta foi um salutar exercício. (Aluno - 2 Portfólio de Estágio - 2012/02)

A proposta geral do curso consistiu em leituras específicas que trabalham alguns dos tópicos mais evidenciados nessa etapa escolar e, concomitantemente com essas leituras, uma escrita articulando o observado e o aporte teórico estudado.

Essa proposta leva em conta a situação da maioria dos alunos, estudantes que não são professores e apresentam relativa dificuldade de relacionar a teoria com a prática, visto que, 
durante o maior bloco de disciplinas teóricas, estiveram sem contato imediato com o campo.

Essa leitura serve como um reforço adicional para relembrarem conteúdos já vistos e situá-los agora dentro de uma realidade. Os tópicos escolhidos foram os seguintes: a) a escola como lugar do saber - considerando que esse espaço, muitas vezes, povoado por inúmeros projetos pode deixar de lado seu maior foco que é o ensino; b) o trabalho com a escrita criativa e autônoma, considerando aqui a queixa dos próprios universitários quanto ao seu próprio processo de aprendizagem da escrita que foi, em geral, restritivo e pautado em exercícios de fixação; e c) a forma de organização e combinados na classe para o desenvolvimento do trabalho. Esse último item vem ao encontro da necessidade de refletir sobre como cada professor utiliza seu saber experiencial para organizar um espaço que permita trocas e gere aprendizagem.

Sobre essa escolha, obtivemos a seguinte observação:

Os textos trabalhados em sala foram gratificantes e importantes para nossa formação. Eles puderam acrescentar conteúdos relevantes para os assuntos abordados. Os trabalhos realizados durante o curso foram proveitosos, pois nos três relatos pegamos diferentes observações analisadas durante o estágio e confrontamos com os textos dados em sala. E assim vivenciávamos aqueles momentos novamente e dialogávamos com os colegas em sala. (Aluno - 7 Portfólio de Estágio - 2012/01)

Além desses três tópicos sobre os quais os alunos realizam um registo escrito que é lido, corrigido e reescrito, se necessário, durante o semestre, há também a escolha de um filme que retrate situações educacionais e sobre o qual os alunos também realizam uma escrita reflexiva. O portfólio final é composto desses textos escritos e debatidos durante o semestre, além de seu plano de aula e avaliação de regência.

O objetivo dessa prática - ler e escrever sobre a leitura e a vivência - é oxigenar o debate com uma construção mais refinada e refletida a partir da escrita que congrega elementos teóricos e práticos, pois possibilita o entrelaçamento de situações partilhadas na escola/campo e na sua trajetória acadêmica. Cremos que os alunos conseguiram perceber o alcance dessa prática lendo a seguinte observação:

Os relatos e desabafos de amigos em sala de aula, assim como os textos estudados, todos estes contribuíram para o período em que fiquei na escola/campo. A partir do momento que vemos a prática em sala de aula de vários profissionais, histórias vivenciadas por amigos, isso só acrescenta para que os acertos continuem a melhorar a cada dia, e que os erros não se repitam. É com esse saber que eu concluo a disciplina com grande satisfação. (Aluno - 4 Portfólio de Estágio - 2012/01)

Uma coisa que sempre refutamos enquanto professor pesquisador foi o hábito de deixar que essas importantes reflexões do aluno só aparecessem ao final do período. O aluno, na perspectiva adotada, é colocado como autor de sua formação, tem voz e vez para expor suas impressões e confrontá-las com diferentes experiências dos colegas. A esse respeito, um aluno elabora a seguinte construção que nos ajuda a compreender a importância dessa atividade:

O autor configura-se assim como uma posição, ou melhor, como uma tomada de posição no mundo, por isso não um autor solitário e criador único e exclusivo da sua obra, o autor onipotente. Pelo contrário, a posição-autor é tanto solitária, como social e em permanente diálogo com os sentidos de seu texto, com ideologias e sujeitos, com 
o mundo. (Aluno - 6 Portfólio de Estágio

- 2012/01)

Um aluno do curso, ao querer exercer essa função de pesquisa e autoria dentro de seu estágio, transformou livremente o seu primeiro relato sobre o saber em uma entrevista com a professora da sala. No seu roteiro constavam questões como: “Qual a relação que as crianças estabelecem com a linguagem, a cultura e o saber?, Como os alunos são mobilizados a desenvolver sua atividade intelectual?” (Aluno - 8 Portfólio de Estágio - 2012/02). O resultado dessa experiência foi muito positiva e abriu a possibilidade para que a professora entrevistada participasse em um momento com o grupo de todos os alunos do curso para dividir sua experiência.

Mesmo em uma condição que está longe da ideal dentro do espaço temporal e material, ainda assim o resultado dessa experiência se coloca como desafiadora e rica para formação profissional. Nesse aspecto, o próprio aluno reflete sobre sua condição de formação e conclui:

O estágio supervisionado e sua importância consistem em teoria e prática aliada na busca constante de aspectos indispensáveis para formação da construção da identidade e dos saberes cotidianos na formação como educador. (Aluno - 5 Portfólio de Estágio - 2012/01)

O trabalho com a Prática de Ensino busca desmistificar a visão pragmática de que existe uma única forma de ensinar e apenas um modo de ser professor, mas, como enfatizamos no processo, cada um deve buscar a sua singularidade.

O ensino é um ofício universal, portador de uma longa história e com origem que remonta à Grécia antiga. Gauthier (1998) sustenta que este ofício ainda mantém em nossos dias um papel fundamental para as sociedades humanas. Entretanto, apesar desta longevidade do ofício de ensinar, "mal conseguimos identificar os atos do professor que, na sala de aula, têm influência concreta sobre a aprendizagem dos alunos, e estamos apenas começando a compreender como se dá a interação entre educador e educandos” (GAUTHIER, 1998, p. 17)

Gauthier (1998, p. 20) usa a sentença "conhece-te a ti mesmo", do oráculo de Delfos, para dizer que ainda se sabe muito pouco a respeito dos fenômenos que são inerentes ao ensino. Argumenta que ao “contrário de outros ofícios que desenvolveram um corpus de saberes, o ensino tarda a refletir sobre si mesmo". Segundo o autor, avançar na pesquisa de um repertório de conhecimentos sobre o ensino possibilita-nos enfrentar duas marcas que historicamente se interpuseram à pedagogia: de um ofício sem saberes e de saberes sem ofício.

$\mathrm{O}$ primeiro diz respeito à própria atividade docente que é exercida sem revelar os saberes que lhe são inerentes. "Apesar do ensino ser uma atividade que se realiza desde a antiguidade, ainda se sabe muito pouco a seu respeito, e que convivemos com certas ideias preconcebidas que contribuem para o "enorme erro de manter o ensino numa cegueira conceitual” (GAUTHIER, 1998, p. 20). Existem formas de conceber a atividade docente que defendem, por exemplo, que ensinar consiste apenas em transmitir conhecimentos, bastando, portanto, conhecer o conteúdo objeto de ensino, ou que é uma questão de talento, bom senso, intuição, ou, ainda, que demanda somente experiência e cultura.

Os saberes referentes ao conteúdo, à experiência e à cultura são essenciais no exercício da atividade docente, mas “tomá-los como exclusivos é mais uma vez contribuir para manter o ensino na ignorância” 
(GAUTHIER, 1998, p. 25) e reforçar a perpetuação de um ofício sem saberes.

O segundo obstáculo diz respeito aos saberes sem ofício, que têm sua origem nas Ciências da Educação, ou seja, são os conhecimentos produzidos nos centros acadêmicos. Muitos desses conhecimentos, segundo Gauthier (1998, p. 27), foram produzidos sem levar em conta as condições concretas do exercício do magistério. Saberes que não se dirigem ao professor real, cuja atuação se dá numa sala de aula concreta onde estão presentes muitas variáveis que interferem no processo de ensino-aprendizagem e exigem tomadas de decisão: "buscou-se formalizar o ensino reduzindo de tal modo a sua complexidade que ele não mais encontra correspondente na realidade”. Para o autor, esse obstáculo contribuiu para a desprofissionalização da atividade docente ao reforçar para os professores a ideia de que a pesquisa universitária não lhes podia fornecer nada de realmente útil, e que, consequentemente, era muito mais pertinente que uns continuassem se apoiando na experiência pessoal, outros na intuição, outros no bom senso, etc.

Para o autor, reconhecer a existência de um repertório de conhecimentos reflete um olhar ressignificado para o professor, que passa a ser visto como um profissional autônomo que delibera, julga e toma decisões.

A experiência concreta do estudante vai aos poucos apresentando situações reais, que saindo de um planejamento estático ganha vida e modifica sua forma de encarar o processo de ensino -aprendizagem e rompe com essas marcas descritas por Gauthier.

Um aluno que realizou sua regência com uma turma de 35 alunos desafiou a turma com reescrita e produção de diferentes tipos de textos - uma atividade com um nível de complexidade elevado. Em sua reflexão analisa que no início achou que não daria conta de tanto trabalho, mas após ser surpreendida com a produção dos alunos bem além do que esperava, conclui:

Refleti muito sobre esta experiência. Percebi a grande importância da dedicação do professor e do aluno também, pois sem esta via de mão dupla a aprendizagem não se estabelece. E nós, enquanto estagiários somos meio alunos e meio professores e também estamos passando por esse processo de aprendizagem. Todo esse aprendizado, todos os conhecimento adquiridos só fazem sentido quando estamos diante de uma turma. (Aluno - 3 Portfólio de Estágio - 2011/02)

Nosso intuito em rever essas reflexões e tentar compreender os saberes docentes a partir de uma trama de relações que ganha diferentes significados, quando o estudante se coloca como professor, converge para perceber o fazer docente como um ofício de saberes e saberes do ofício, que não pode jamais ser prescritivo, pois cada educador é subjetivo e atende a demandas subjetivas; porém, podemos inferir no quanto é possível partilhar uns com os outros sobre formas de ser professor que mobilizam saberes e nos apontem pistas para iniciar nessa profissão. Terminamos esse diálogo entre os saberes docentes e a reflexão de alunos em processo de formação com a palavras de um aluno sobre sua futura atuação:

As práticas observadas reiteraram o meu desejo de ser um educador de verdade. Um educador integral, responsável, preparado, preocupado, crítico, exemplar, alegre, comprometido, profissional, enfim, ético. Espero que, um dia, utilize todas essas reflexões na minha prática educativa. E que seja possível essa prática se eticamente responsável. Esse é meu desejo. (Aluno - 2 Portfólio de Estágio - 2012/02) 


\section{Prática de Ensino na gestão: o conselho pedagógico e o projeto político pedagógico}

A participação dos estagiários nos Conselhos foi autorizada em uma das escolas observadas. Nos relatórios foi destacada a facilidade de acesso que tiveram para participarem do Conselho Pedagógico (COPE), presenciando os conselhos de $2^{\circ}$ e $3^{\circ}$ bimestres de 2010, 2011 e 2012. Entrevistaram uma aluna que tem participado dos conselhos desde 2010 que considerou:

Hoje eu tenho participado mais e entendo a importância da representação no conselho. Tivemos reuniões com a coordenação pedagógica para a discussão sobre o objetivo da presença dos alunos. Tenho anotado as decisões e levo para minha turma de $3^{\circ}$ ano. Também temos um espaço de discussão na sala de aula e só os alunos participam. Levo as reivindicações para o conselho. Ainda não temos muita atenção de alguns professores, mas a coordenadora diz que é a mudança acontece devagar. (Aluna da turma da $3^{\mathrm{a}}$ série $\mathrm{B}-19$ anos)

Desse ponto de vista, o depoimento revela que a participação trouxe orientações através da coordenadora quanto ao desempenho da função e que existem condições para uma melhor organização. Começam a aflorar os resultados mesmo com algumas dificuldades apontadas. Em 2010 e 2011 a situação era diferente e de acordo com os alunos estagiários, o desenvolvimento desse conselho acontece em duas partes. No primeiro momento, os representantes dos jovens alunos informam dados referentes de cada turma, como por exemplo: as conquistas e dificuldades de aprendizagem da turma nas diferentes disciplinas, a motivação a partir das estratégias pedagógicas dos professores, os interesses comuns dos alunos, a participação nas atividades intra e extraescolares, dentre outros. Ainda neste momento, os professores expressam suas opiniões quanto ao comportamento, valores e conteúdos considerados importantes para o desenvolvimento da formação profissional.

No segundo momento, os alunos deixam o conselho, restando somente o grupo de docentes, a direção, a coordenação e funcionário da secretaria. Cada um desses grupos possui um tempo determinado para expor suas considerações sobre assuntos diversos, que devem ser melhor trabalhados em sala de aula. Os responsáveis dos alunos devem ser chamados, seja pelo baixo rendimento nas disciplinas, seja por problemas de comportamento. Após esse debate, algumas decisões são tomadas de forma conjunta e um cronograma de ações é elaborado.

Em outro dia é marcado uma reunião com os discentes e são mostrados os aspectos positivos de cada turma, e alguns aspectos que precisam ser transformados. Também as ações a serem desenvolvidas são divulgadas, e os alunos podem se manifestar. Alguns alunos fazem sugestões e solicitam a mudança de ações, mas nos conselhos assistidos em 2010 e 2011 essas sugestões não foram acatadas pelos docentes, coordenadores, direção e outros. Nas discussões em classe os alunos estagiários reconhecem a importância dos conselhos, mas ressaltam, nas reflexões, que os conflitos ficam restritos aos desentendimentos interpessoais, os interesses divergentes e as sugestões dos jovens que frequentam o Ensino Médio são desconsiderados. A gestão que pretende ser democrática deve reconhecer que a escola abriga tensões dialéticas entre os seus modos próprios de regulação. Essa organização ainda está presente para o desenvolvimento do Conselho, mas fica evidente a tentativa de ampliação e conquista no processo.

A escola é o lócus de produção de leis, comportamentos, habilidades, conhecimentos, orientações e regras. A gestão do Conselho 
e do PPP inseridos na cultura escolar são as possibilidades de professores, gestores, alunos e outros assimilarem a coletividade. Em Conselhos assistidos referentes às classes de $3^{\text {a }}$ série em 2010 e 2011, foi levantado o problema da indisciplina. Os professores discutiram a proposta de "apertarem nas provas", "fazerem advertências individuais" e “chamarem os pais”. Essas medidas seriam direcionadas por uma comissão formada por professores, coordenadores e direção.

Percebemos que o monitoramento utilizado precisa ser decifrado quanto ao entendimento de qualidade de ensino e à função dos diferentes atores presentes na cena educativa. Assim, se evidenciaria os modelos organizacionais que estão na base da gestão das escolas, identificando as grandes tendências adotadas, visando atingir os objetivos da escola ou do sistema. Ou seja, seria evidenciada a forma como as atividades estão discriminadas, como os tempos estão divididos, a distribuição das tarefas e competências, as relações de hierarquia que refletem as relações de poder, entre outras características inerentes à forma como o trabalho é organizado (OLIVEIRA, 2008, p. 133)

Observa-se a existência de um processo contraditório em que, ao mesmo tempo, se apregoa o discurso da participação na definição de propostas e projeto político pedagógico para as escolas, investe-se em competitividades entre as turmas e também se descentralizam algumas ações. Essa descentralização é percebida quando o gestor é chamado não só para gerenciar recursos, como também para captar recursos, criar parcerias e ser responsável pelo sucesso e fracasso da escola.

O conflito fica evidente quando se observa que as práticas de gestão nem sempre estão abertas à presença dos que querem ser ouvidos para participarem das tomadas de decisões. Nestes termos, a gestão democrática deixa de ser aquela que busca a efetivação da educação como direito social, assim como acesso, permanência e qualidade referenciada (CABRAL NETO, 2000, p. 38).

Democratização da gestão do ensino público nos estabelecimentos oficiais significa obedecer aos princípios da participação dos profissionais da educação na elaboração do projeto pedagógico da escola e a participação das comunidades escolar e local em conselhos ou equivalentes (BRASIL, 2001, p. 34)

Essas mudanças indicadas na legislação educacional são importantes para o desenvolvimento escolar e, sobretudo, porque podem repercutir no trabalho educativo e nas estratégias de ação dos diretores, coordenadores e professores na condução de propostas pedagógicas na escola.

Contudo, em algumas situações educacionais nesses colégios de Ensino Médio, em que foi possível o estágio, observou-se dois pontos de convergência: o primeiro deles é que a elaboração, implementação e avaliação dos PPPs não acontecem mediante a ação participativa da comunidade escolar; o segundo diz respeito às razões que emperram a construção coletiva por parte dos professores.

Alguns pontos comuns norteiam a visão do Projeto Político Pedagógico nos colégios de Ensino Médio. Ressaltamos que o documento faz parte de uma exigência da Secretaria da Educação XXXXXX. Desde 2005 há mais rigor na cobrança e inspeção do projeto. Nos colégios os gestores e professores confirmam a importância da construção compartilhada do PPP, mas isso não acontece nas escolas.

Pais, alunos, professores e funcionários não participam da tomada de decisões na fase de planejamento até a implementação da avaliação das atividades e ações escolares. Observa-se que a participação da comunidade escolar fica restrita ao conselho escolar. Apesar de a equipe gestora atender à determinação legal de elaboração do PPP, as linhas 
gerais do projeto chegam de forma pronta e é comunicada aos professores no início do ano letivo para, a partir dessas diretrizes, serem construídas outras ações e subprojetos. Assim, durante o ano são incorporados a esse documento os projetos que acontecem ao longo do ano letivo, e essa ampliação e registro ficam a cargo dos coordenadores.

Entendemos, pelo que foi lido nos PPPs e colocado nos depoimentos dos gestores e professores, que predomina uma certa fusão e confusão em torno dos conceitos de liderança, descentralização, escola pública, o que, como analisa De Rossi (2005), dificulta o processo coletivo decisório. As tipificações apresentadas por Costa (2003) mostram que os PPPs observados correspondem:

- ao "Projeto - vago" que é aquele que se traduz num documento de intenções e objetivos gerais pouco precisos, sem metas e com consensualidade, isto é, sem pressão dos atores, pois tal projeto permite que cada indivíduo ou grupo siga seu próprio caminho...

- ao Projeto - ofício que é aquele que “serve para enviar”, que dá por concluído nas fases de redação e aprovação do documento escrito e sua apresentação formal às instâncias da administração educativa, e encontra-se à disposição na gaveta para quem solicitar....”

As potencialidades do Projeto Político Pedagógico estão nos princípios que visam superar a centralização e controle hierárquico. Nestes termos, o PPP é, ao mesmo tempo, político, no sentido do compromisso da escola com a formação do cidadão, e pedagógico, no sentido de definir ações educativas, construções curriculares, formação continuada de professores, para que a escola possa atingir seus propósitos e sua intencionalidade (VEIGA, 2001, p.13). A utopia é essencial para agregar pessoas em torno de grandes ideais emancipadores. Em consulta ao PPP de um dos colégios, está o seguinte registro:

Um PPP é composto de uma série de documentos que vão se juntando ao longo do ano letivo, ficando concluído apenas em dezembro, quando terminamos nosso planejamento. No início do ano, mais especificamente em fevereiro durante a Semana Pedagógica, a Direção do colégio, juntamente com a Equipe Pedagógica apresenta ao Corpo Docente e aos demais funcionários as ideias norteadoras do PPP. É importante lembrar que no mês de janeiro são analisadas as propostas básicas determinadas pela SEEDUC, que também determina o dia em que o ano letivo se inicia e o período em que serão realizadas as atividades trabalho e administradores de recursos escassos, ao contrário do que é alardeado quanto à gestão participativa, democrática e descentralizadora nas escolas públicas (FRANÇA, 2009, p.68).

A interpretação dessas condições exprimem os conflitos vividos pela direção e coordenação, que não conseguem, seja pela falta de tempo ou preparo pedagógico, responderem às demandas de repensarem suas formas de avaliação, elaborar conjuntamente seu PPP e consolidar práticas democráticas com características mais duradouras, o que só será possível com discussões com vistas ao desenvolvimento da importância da democracia em todos os níveis de atuação social.

\section{Considerações finais}

O entrelaçamento das vozes docente e discente no âmbito do estágio constituem a sua riqueza. Pensar para além de um grupo de estudantes e um professor e perceber que essa teia de relações está alicerçada em uma rede ampliam nosso raio de alcance e contribui para uma formação que deseja ser partilhada e realizada dentro de um coletivo. 
O aluno que chega para fazer seu estágio nas Séries Iniciais já teve um ganho efetivo quando estudou profundamente as Políticas Públicas e as formas de gestão específicas da educação, que são atreladas ao contexto pedagógico e de formação humana.

Inserir dentro de um curso uma continuidade de ação que está além de um conteúdo que é pré-requisito, mas que está ligado por uma coerência de dinâmica e conceitos, contribui para que o aluno não sinta o desvio de passos, mas possibilita construir elaborações que realmente vejam a escola em seus múltiplos aspectos. Dessa forma é possível romper com o senso comum, elevar o aluno ao pensamento pautado em reflexões da dinâmica complexa da escola, pois não sabemos em que esfera da educação irá atuar, mas, independentemente de sua futura escolha, a noção de totalidade do objeto de estudo foi perseguida dentro de nossas práticas.

Um aluno nos ajuda concluir, utilizando uma forma possível de troca de papéis, quando escreve:

Percebemos que essa reflexão gerada pelo estágio nos possibilita pensar a prática da sala de aula a partir da teoria e desta forma trabalhar em função do desenvolvimento do aluno. Hoje nós observamos, amanhã poderemos ser observadas e desta forma contribuir com a formação de outros. A educação nos possibilita essa dinâmica de ensinar e aprender, logo, percebemos que os professores que nos acolhem não sabem tudo, e nem nossos professores formadores da universidade tem a resposta para tudo, e assim nos constituímos educadores. (Aluno - 2 Portfólio de Estágio - 2012/02)

\section{Referências}

CABRAL NETO, A.; ALMEIDA,M. D. Educação e gestão descentralizada: conselho diretor, caixa-escola, projeto políticopedagógico. Em Aberto, Brasília, v.17, n.72, p.35-45, jun. 2000.

CHARLOT, B. Relação com o saber, formação dos professores e globalização: questões para a educação hoje. Porto Alegre: Artes Médicas, 2005.

COSTA, J. A. Modelos organizacionais de escola e qualidade de ensino: o futuro da incursão especulativa. In: OLIVEIRA, D.; ROSAR, M. de F. Política e gestão da Educação. Belo Horizonte: Autêntica, 2008.

DE ROSSI, V. L. Gestão do projeto políticopedagógico: entre corações e mentes. São Paulo: Moderna, 2005.

FRANÇA, M.; BEZERRA, M. C. Política educacional: gestão e qualidade do ensino. Brasília: Liber Livro, 2009.

GAUTHIER, C. Por uma teoria da pedagogia: pesquisas contemporâneas sobre o saber docente. Ijuí: Unijuí, 1998.

LEÃO, G.; DAYRELL, J. T. Juventude, projetos de vida e ensino médio. Educação e Sociedade, Campinas, v. 32, n.117, p.10671083, out. 2011.

OLIVEIRA, D. A.; ROSAR, M. de F. Política e gestão da educação. Belo Horizonte: Autêntica, 2008.

SANDER, B. Política, gestão e qualidade do ensino. In: FRANÇA, M.; BEZERRA, M. C. Política educacional: gestão e qualidade do ensino. Brasília: Liber Livro, 2009.

VEIGA, I. Projeto político-pedagógico: novas trilhas para a escola. In: FONSECA, M.; VEIGA, I. P. A. (Orgs.) As dimensões do projeto político-pedagógico: novos desafios para a escola. Campinas, Papirus, 2001. 